\title{
The social dilemmas of climate change and antibiotic resistance: an analytic comparison and discussion of policy implications
}

\author{
Niklas Harring (iD ${ }^{1,3 凶}$ \& Eva M. Krockow ${ }^{2,3}$
}

Climate change and antimicrobial resistance are two of humanity's most imminent problems. Reducing the use of fossil fuels and antibiotics is essential for managing the threats, and theory-based policies are required to stimulate urgently needed behaviour change. This article analyses climate change and antimicrobial resistance within the context of game theory. Previous literature has identified these problems as Commons tragedies, where inherent incentive structures encourage selfish overuse of existing resources. While the game theoretical models provide a helpful conceptual basis, the present analysis suggests discrepancies between some of the theoretical assumptions and the practical realities of climate change and antimicrobial resistance. These include complex networks of decision makers, non-binary choice contexts complicated by temporal and spatial distance between choices and outcomes, and different ethical implications of resource overuse. Policy implications are discussed, highlighting the need of global agreements for coordinating local initiatives for both dilemmas. However, different target groups may be necessary to address the existence of gate keepers (e.g., medical prescribers) in antibiotic use. Additionally, while certain policies types (e.g., information policies) apply to both dilemmas, more nuanced ethical considerations mean that some economic policies (e.g., punitive policies) may be limited to managing climate change.

\footnotetext{
${ }^{1}$ Centre for Collective Action Research, Department of Political Science, University of Gothenburg, Gothenburg, Sweden. ${ }^{2}$ Department of Neuroscience,

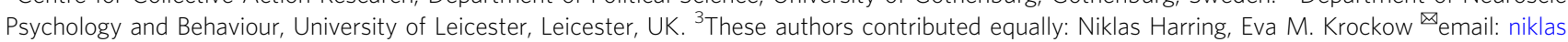
harring@pol.gu.se
} 


\section{Introduction}

limate change (CC) and antimicrobial resistance (AMR) are two of humanity's most imminent existential problems (IPCC, 2018; O’Neill, 2016). A global temperature rise above 2 degrees Celsius is expected to lead to for example an increased frequency of droughts and flooding, generating immense human suffering (IPCC, 2018). Similarly, by 2050, about 10 million people are expected to die every year from the consequences of AMR (O’Neill, 2016).

Scholars have acknowledged that the commonalities of CC and AMR are not limited to their urgency, severity and global dimension. They may also be interconnected, with climate change being a contributor to AMR, for example through the spread of disease vectors (Helwig, 2019). Additionally, the two problems share a similar underlying structure: They can both be understood as social dilemmas, in the sense that individual rationality is at odds with collective interests (Anomaly, 2010; Roope et al., 2019). People's consumption of fossil fuels and antibiotics is rational at the individual level, because it serves short-term, personal benefits: Fossil fuels provide comparatively cheap and easy access to energy needed for everyday conveniences (e.g., driving cars); and antibiotics provide efficient treatment for bacterial infections. Even though antibiotic medication often comes at a cost of immunocompromise or other side effects, these disadvantages are not well-known among the general public (Davies et al., 2013), or frequently dismissed by healthcare practitioners in the face of larger medical threats such as potential sepsis and death (Krockow et al., 2018). It is important to acknowledge the lack of viable alternatives to fully replace fossil fuels and antibiotic medication while maintaining the current standard of living. Instant cessation of all use of fossil fuels, for example, would likely lead to a collapse of the global economy and infrastructure, and antibiotics save lives and reduce suffering worldwide. However, current consumption of fossil fuels and unnecessary use of antibiotics are costly for collective goals, which include preventing rampant $\mathrm{CC}$ and decelerating the spread of AMR.

The social dilemmas of CC and AMR require behavioural strategies (e.g., Colman et al., 2019; Milinski et al., 2008; Roope et al., 2018) and coordinated action to manage (Jagers et al., 2020). However, the existing literature falls short of a systematic conceptualisation and direct comparison of CC and AMR to form the theoretical basis for comprehensive policy suggestions.

In this article, we propose to provide this urgently needed systematic analysis of CC and AMR, using game theory as a conceptual basis. We aim to provide an analytical comparison between the theoretical literature and the reality of CC and AMR. Additionally, we will present a conceptual comparison between the two social dilemmas. Both of these objectives will feed into the overall aim of discussing policy strategies to tackle CC and AMR. Specifically, we aim to address three main research questions: (1) How do core assumptions of game theory correspond to the realworld cases of CC and AMR? (2) How do CC and AMR compare in their social, political and behavioural challenges? and (3) What are the policy implications of this theoretical analysis, and what considerations need to be made when designing policy approaches to target CC and AMR? The remainder of this article will be structured as follows. First, we provide a theoretical overview of social dilemmas in the context of game theory. Next, we will present a step-by-step analysis of CC and AMR against the typical features of social dilemmas. Then, we will compare collective action approaches targeting AMR and CC, and contrast both with recommendations from game theory. Finally, we will discuss the implications of our analysis and make theory-based recommendations about the types of collective action that may prove most successful in different types of social dilemmas including CC and AMR.

\section{Social dilemmas}

Both CC and AMR have been argued to have the underlying structure of a social dilemma (e.g., Colman et al., 2019; Milinski et al., 2008; Rogers Van Katwyk et al., 2019; Roope et al., 2018). ${ }^{1}$ The term describes choice situations with two properties: "(a) each individual receives a higher payoff for a socially defecting choice $[\ldots]$ than for a socially cooperative choice, no matter what the other individuals in society do, but (b) all individuals are better off if all cooperate than if all defect" (Dawes, 1980, p. 169). Hence, social dilemmas are situations where individual rationality is at odds with collective interests (Anomaly, 2013; Roope et al., 2019). More specifically, CC and AMR are examples of Commons tragedies, where an existing common resource-a stable climate and antibiotic drug efficacy-are in danger. In Hardin's original example of a "Tragedy of the Commons", several farmers compete for the resources provided by a public meadow (the "commons") (Hardin, 1968). The meadow offers free food for their sheep, and the more sheep each farmer sends to graze, the higher their personal benefit will be. The meadow, however, can only accommodate a limited number of animals, and if maximum capacity is surpassed, the grassland will degrade, thus making future use impossible and harming all farmers in the long run.

\section{Analytic comparison of CC and AMR}

Next, we will consider the dilemmas of CC and AMR in the context of key assumptions underlying Hardin's (1968) classic example, subdivided into assumptions regarding the decision makers, the common good and the decision strategies available in the choice context.

\section{Decision makers}

Autonomy. In the classic Commons tragedy, all decision makers are assumed to make their own, independent choices. However, in real-life dilemmas, representatives exist who often take on mediating roles or make choices on behalf of others. In the case of AMR, many nations have antibiotic gate keepers in the form of medical prescribers and pharmacists to formally regulate antibiotics access of (medically naive) patients. These cases of decision representation have previously been modelled as principalagent problems (Tarrant et al., 2019), which conceptualise the representative decision maker as agent and the passive stakeholders as principals. Principal-agent relationships introduce an additional level of complexity to social dilemmas, because they allow room for conflict of interest between principals and agents. For example, in the context of AMR, it has been argued that antibiotic gate keepers may wish to reduce their antibiotic prescribing but that this wish is difficult to reconcile with patient expectations (Krockow and Tarrant, 2019; Tarrant et al., 2019). While more decision autonomy exists in the case of CC, people's choices are often limited indirectly, for example based on available infrastructure. It is difficult to use electric vehicles if there are no charging stations, and sometimes dangerous to commute by bike if there are not proper bicycle lanes.

Symmetry. The classic Commons tragedy assumes decision makers with equal roles and equal impact of their decisions (Colman, 2013). However, both CC and AMR are characterised by the existence of various types of decision makers, all with different roles and impact. In the context of CC, decision makers include a heterogeneous range of producers, consumers (individuals and larger organisations), fossil-fuel companies and more. 
The impact of these decision makers' choices differs greatly according to their role. While any individual consumer is unlikely to make a large contribution to CC, multinational companies often have significant carbon footprints. Similarly, in the healthrelated context of AMR, the diverse range of decision makers includes different types of doctors, patients, healthcare institutions and pharmaceutical companies. Additionally, these decision makers will be influenced by their respective national contexts and healthcare systems including differences between private and public healthcare (Tarrant et al., 2021). Given these various levels of impact, one solution is therefore to identify larger "superusers" (Quail et al., 2017), e.g., actors within the fossil-fuel or pharmaceutical industry, and ensuring they are held accountable for their imminently more significant actions.

Another aspect of symmetry are equal utility functions. Contrary to Hardin's (1968) Tragedy of the Commons, where every farmer bears the same cost associated with the degradation of the commons, CC and AMR are characterised by inequalities between stakeholders. Consequently, the preservation of the commons is more important to some stakeholders than to others, and these different interests may prevent globally acceptable norms for cooperative action. For example, individuals inhabiting coastal regions prone to increased flooding under rising temperatures are likely to suffer disproportionately from the effects of CC. Similarly, in the context of AMR, people living in low- and middle-income countries with less hygiene and infection control are likely to be more affected by a lack of effective antibiotic drugs than those living in richer countries.

Information. The original Commons tragedy assumes the decision makers' complete information about the decision context, meaning they know the available strategies, the associated outcomes, the number of other decision makers involved in the problem and all their respective outcomes (Colman, 2013). In the case of CC and AMR, however, some decision makers may not even be aware that a problem exists. While media warn about the dangerous consequences of $\mathrm{CC}$ and AMR, exposure to such outlets depends on the geographic and socio-economic background of the decision makers. Even if information is available, many people may hold incorrect or incomplete beliefs about the respective dilemmas. Lay people depend on the soundness of scientific findings and on the accurate communication of those findings by media and national organisations. In the case of representative decision makers acting on lay people's behalf (e.g., doctors or politicians), lay people have to further rely on those decision makers' competence. This reliance on expert knowledge and judgement requires a large amount of trust on behalf of the lay population. Nevertheless, this trust risks being undermined in cases of fake news or filtered news reporting in countries lacking free journalism. In the context of AMR, for example, trust in the national healthcare system may be a crucial determinant of patients' acceptance of their doctors' antibiotic prescribing choices (Robertson et al., 2018). Given this complex information context, it is hardly surprising that surveys of patients repeatedly show misguided beliefs about AMR and antibiotic use (Hwang et al., 2015). In the case of CC, misinformed individuals and lobbyists frequently attack scientific knowledge, thus undermining trust (Dunlap and McCright, 2011).

Perfect information. In many laboratory studies of social dilemmas, previous choices of other decision makers are known. This most commonly applies when participants play repeated rounds of the same public goods game or if they are given the option to punish non-cooperative individuals through payoff deductions. Empirical research suggests that cooperation may increase if information about other participants' (previous) choices is available. This is because perfect information may help to create social norms for behaviour (including associated emotions of shame or guilt) and it may allow for the sanctioning of free riders (for reviews of the experimental literature see Bowles and Gintis, 2008, and Ostrom, 2000). Yet, real-life dilemmas such as CC and AMR often lack this level of transparency. At national or organisational level, greenhouse gas emission levels sometimes need to be declared and the information is passed on by relevant authorities and environmental protection agencies. However, much less information is available at the individual level and the average citizen may have difficulties singling out defectors or recognising co-operators. The same is true for antibiotics. While information about the total use of antibiotics is typically aggregated at the national level (or sometimes at local levels of individual healthcare institutions), individual antibiotic usage is difficult to track, for example, due to the limited existence of electronic prescribing and monitoring systems. In both real-life dilemmas, decision makers lack information about the choices of their peers and this makes it difficult to establish the carbon footprint or overconsumption of antibiotics by others, and to discipline defectors.

\section{The commons}

Renewability. In the classic Tragedy of the Commons, the common good is finite and non-renewable: Subsequent to overgrazing, the meadow turns into fallow land and ceases to benefit any farmer. The characteristics of the commons involved in CC and AMR, however, might be more complicated. In the context of CC, a stable and comfortable climate is the resource at stake, and this resource is threatened by greenhouse gas emissions. However, in contrast with Hardin's (1968) grassland resource, the climate cannot become "depleted". A more useful concept is that of absorptive capacity, which refers to the amount of greenhouse gas emissions that can be absorbed by the environment without producing lasting damage to the climate. Depending on this absorptive capacity, emissions may lead to different possible climate states that vary in their hospitality for human life. In contrast, AMR develops when particularly resistant bacteria survive the use of antibiotics and subsequently pass on their naturally resistant genes to other bacteria. This evolutionary process of genetic adaptation ensures survival of the resistant microbes and is therefore unlikely to be reversible (Alison et al., 2016). However, ongoing research in the biomedical sciences is focused on discovering new antibiotic drugs (Davies and Davies, 2010), increasing efficacy of existing antibiotics through "adjuvenants" that prime our immune system (Anomaly, 2020), and alternative treatment options for bacterial infections such as phage therapy (Lin et al., 2017). Hence, even though there is a danger of antibiotic drug efficacy becoming depleted, significant scientific developments could lead to a sudden change in the situation of the commons. However, it is currently impossible to predict the likelihood or timeframe of such scientific progress (Anomaly, 2020).

Tangibility and necessity. In Hardin's (1968) Tragedy of the Commons' example, the commons is a highly tangible resource: a meadow whose degradation is highly visible and affects all farmers in equal measures. In contrast, both CC and AMR involve much more abstract resources and are therefore less tangible in the sense that (a) the depletion of the resource is not visible to the naked eye (e.g., Rose, 2009) and (b) the depletion of the resource may not affect all stakeholders to an equal extent. Both the concept of climate stability and antibiotic drug efficacy require underlying knowledge and a capacity to understand scientific processes. Additionally, given the longer-term 
consequences of using fossil fuels or antibiotics, CC and AMR are difficult to observe and track by individual decision makers. In fact, with AMR occurring at the invisible level of microbes, even highly educated members of society, including non-specialist doctors, are often unable to gauge the scope of the problem. Furthermore, in the classic Tragedy of the Commons (Hardin, 1968), the resource is essential to the survival of all decision makers because no alternative resource exists. This makes the degradation of the commons highly relevant to every member of the community, and therefore very tangible. By comparison, CC and AMR lack concreteness compared to the problem of a deteriorating grassland. This may result in decreased salience of the problem and a lacking sense of urgency or necessity to preserve the resource at stake.

\section{Strategies}

Choice structures. In the classic social dilemma situation, the available strategies are clear; each actor has to decide between cooperation and defection. Real-life dilemmas, on the other hand, rarely have such a simple decision structure. In the case of CC, hardly any choices are categorical. For example, when deciding about the use of fossil fuels, few decision makers face an all-ornothing type dilemma, which would require choosing between not having a car and using a car for every single journey. Instead, their choice may fall along a continuum, requiring nuanced decisions about how often to use a car, whether to engage in car share opportunities and what car model to purchase in the first place. These nuanced decisions may often be guided by social norms (Ostrom, 2000).

In the case of AMR, the available strategies may be even more complex and it is often impossible to identify a strategy of "appropriate" antibiotic prescribing (Tarrant et al., 2020). Typically, any treatment decision is preceded by a sequence of choices, which form part of a longer decision making process. This, in turn, is further influenced by macro- and mezzo-level factors such as the state's healthcare policy, pharmaceutical distribution and health insurance systems (Tarrant et al., 2021). Initially, a general (binary) judgement about the existence of a bacterial infection has to be made. This will be followed by decisions about the type of antibiotic (e.g., broad-spectrum vs. narrow-spectrum), the mode of delivery (oral vs. intravenous), and the treatment length and dosage (Rawson et al., 2016). Both treatment length and dosage are continuous variables and the categorical choice about the drug type has a large number of different options. Given the complicated choice structures, identifying collectively optimal strategies in the cases of CC and AMR can be challenging. Behavioural recommendations will invariably be complex and vary for each actor in the dilemma.

Labelling of strategies. In the classic social dilemma situation, the individual self-interests are in conflict with the interests of the collective. Hence, scholars typically distinguish between selfish defection and community-oriented cooperation. These clear labels have strong ethical connotations, marking defection as the socially undesirable choice. For example, in the context of CC, overuse of fossil fuels is typically interpreted as an undesirable, selfish action. However, such labelling of strategies is of course oversimplified, for example there are ethical arguments for why poor people should be allowed to emit more carbon (Jakob and Steckel, 2014) and people can emit climate gasses aiming to do good. In the case of AMR, to label antibiotic use or prescription as selfish defection is naïve or even wrong. In very few instances of antibiotics overuse are doctors assumed to be motivated by concerns conventionally understood as selfish. The incentives for overprescribing are hugely complex. Doctors typically benefit from prescribing antibiotics because it reduces their cognitive load when making treatment choices, serves to satisfy patient demands, or is a practical response to limiting factors of the healthcare system (e.g., lack of healthcare insurance or over-thecounter access to antibiotics), (Krockow et al., 2018). Yet, the main drivers identified across a variety of both high and lowincome countries are a concern for the deterioration of the patient and an aversion to diagnostic uncertainty that may be a symptom of fatal conditions such as severe sepsis (Krockow et al., 2018). Given the ultimately pro-social motivations underlying many prescribing decisions, it is therefore difficult to univocally condemn excessive prescribing as a morally selfish act.

Link between action and outcome. Classic Commons tragedies are characterised by causal relationships between decisions and outcomes. For example, the extent of the grassland's deterioration is a direct consequence of the farmers' choices on how many animals to send for grazing. This causality, however, may not exist across all real-life social dilemmas. In both CC and AMR, it is impossible to predict or measure the effect of each individual choice on the depletion of the resource at stake. For example, an individual's decision to commute by car rather than by bike leads to higher emissions of $\mathrm{CO}_{2}$. This in turn increases the concentration of greenhouse gasses in the atmosphere, whichthrough the Greenhouse effect-are linked to increased global temperatures. Higher temperatures subsequently lead to droughts and rises in sea level, both of which have negative consequences for human societies. However, given this complex chain of events, which may partially be influenced by additional decision makers and situational factors, it is impossible to make direct causal inferences between an isolated choice and CC, not least because any one consumer only makes a very small contribution to the problem through their individual choice. In the context of AMR, the situation is to some extent even more complicated. The development and spread of drug-resistant genes in microbes is still not fully understood, and it is unclear to what extent the use of different antibiotics promotes AMR in the environment (Laxminarayan et al., 2013). Scientists typically agree that broadspectrum variations of antibiotics are more damaging than narrow-spectrum antibiotics, because they are effective against a wider range of pathogens at the cost of incurring higher levels of resistance. Yet, it is impossible to measure and quantify their respective contributions to the problem (Alison et al., 2016). This leads to a vague, probabilistic relationship between action and outcome, which may prevent decision makers from acknowledging the damaging consequences of resource overuse and from taking responsibility for their own choices of overconsumption.

Temporal distance. Large-scale dilemmas such as CC and AMR are frequently characterised by both temporal and spatial distance between decision makers (Jagers et al., 2020). The most negative consequences of both CC and AMR are expected to affect future generations (Fitzpatrick et al., 2019; Tarrant et al., 2019). Even though current society already experiences some of the symptoms of CC such as higher temperatures and increased flooding, these effects are expected to significantly increase in gravity over the next decades. Similarly, even though some current patients already suffer from untreatable infections caused by multi-drugresistant "superbugs", in many cases effective second-line antibiotics are still available to treat infections that fail to respond to the first treatment choice. This means that those decision makers currently emitting carbon or overconsuming antibiotics are not the ones to ultimately bear the consequences. The result is temporal distance between decision and outcome, which complicates the social dilemma. In Hardin's (1968) Commons tragedy, on the other hand, all farmers suffer the consequences of repeated 
defection. Thus, all of them have some interest in preserving the public good of the grassland. In the case of CC and AMR, this interest is weakened, meaning that the incentives to participate in or reinforce cooperative action are lower.

Spatial distance. Finally, while game theory poses theoretical constraints on the geographic perimeters of the Commons tragedy, this is rarely the case in real-life dilemmas. Hardin's (1968) example of farmers sharing a common grazing area limits the dilemma to a restricted number of decision makers and does not allow for external stakeholders beyond the local community. However, both CC and AMR are problems of global dimensions, which cannot be studied or targeted in the isolation of one geographic area. For example, the geographic origin of greenhouse gas emissions is of little importance since gasses do not respect geographic borders and any emission contributes to the global challenge of CC. Hence, the citizens of all nations can be affected by isolated actions of a few consistent defectors, which are out of their governmental reach. This is similar in the case of AMR, where drug-resistant bacteria frequently spread through international travel (Eggleston et al., 2010). Thus, even if antibiotic prescribing within a specific local hospital is tightly governed and inappropriate treatment thus minimised, AMR can easily be introduced through patients, who have previously visited other regions or countries. This global interdependence of spatially distant decision makers further weakens the direct link between the action of overconsumption and the outcome of degradation of the commons. As a result, individual decision makers could doubt their responsibility for the overall dilemma or their capacity to make a meaningful change to the situation. Evidence for this has been provided by recent interview studies of doctors, who frequently blamed other decision makers for the increasing levels of AMR and expressed their feelings of powerlessness in the face of the complex global problem of AMR (Krockow et al., 2018).

\section{Discussion}

As shown by our analysis in the previous section and supported by earlier contributions to the literature (Anomaly, 2020; Roope et al., 2019), CC and AMR are complex but still share key features of social dilemmas. This points to the relevance of game theory for informing analysis and improving understanding of the two problems. In both cases, (1) a common resource (stable climate and antibiotic drug efficiency) is at risk of being lost and (2), the inherent incentive structures encourage overuse of the resource by individuals, thereby aggravating the problem. Even though each individual's contribution to the problem is small, largespread levels of overuse may create existential challenges for the entire community. Hence, the commons can only be preserved if a critical mass of decision makers choose to collaborate and sacrifice individual gains. Results from experimental games and field studies have identified a number of "facilitators" (Jagers et al., 2020) that increase the likelihood of cooperation in social dilemmas. Information and choice transparency, for example, can contribute to cooperative actions by increasing motivations to build a positive reputation (Fehr and Gächter, 2000; Fischbacher et al., 2001; Ostrom and Walker, 2003). Furthermore, incentive structures such as punishments and rewards can promote the willingness to cooperate (Balliet et al., 2011; Balliet and van Lange, 2013; Fehr and Gächter, 2000).

However, while these insights are helpful from a theoretical point of view, their direct applicability to policy development is not always straight forward in the contexts of CC and AMR, which are complex and large-scale problems. Our detailed, theory-based analysis showed important discrepancies between some of the game theoretic assumptions of social dilemmas and the real-life contexts of CC and AMR. Awareness of these discrepancies is crucial for the academic discussion of these issues and for well-motivated policy analysis.

Specifically, the large-scale, complex networks of decision makers with varying roles and interests complicates communication and reputation building that could reinforce reciprocal action. Additionally, the often non-binary choices in the context of CC and AMR are difficult to label, and are further complicated by temporal and spatial distance between choices and outcomes, thus making it almost impossible to hold defectors accountable for their actions. Especially in the case of AMR, where overuse of antibiotics is often motivated by the prescribers' altruistic patient concerns rather than selfish interests, this incurs problems for the application of punishment and rewards.

Given these factors, a common argument is that third-party intervention is necessary to sustain the common resources (Jagers et al., 2020; Mansbridge, 2014; Olson, 2009; Ostrom, 1998). For example, Ostrom claims that collective action problems are the "the core justification of the state" (Ostrom 1998, p. 1). Dealing with large-scale collective action problems, many facilitators such as direct reciprocity and reputation that can help individuals to sustain the commons are no longer present. Hence, there is a demand for a third-party-in many instances the state-which has the power to coerce or encourage actors to cooperate (see Jagers et al., 2020).

In the remainder of this section, we will discuss the potential for such interventions in the context of CC and AMR policy, making use of results from experimental economics. In particular, we will address the following three key policy dimensions: (1) scale for action, (2) target group and (3) policy design.

Scale for action. While CC is negotiated at an international level and national policies are implemented, most studies of antimicrobial stewardship use smaller-scale intervention designs, for example focusing on individual hospitals or primary care trusts. These small-scale approaches are unlikely to be sufficient for addressing the wider, global problem. Indeed, scholars made calls for international treaties and institutions on antibiotics similar to those on the topic of climate change (Andresen and Hoffman, 2015; Anomaly, 2010; Ardal et al., 2016; Podolsky and Lie, 2016; Premanandh et al., 2016). A notable example includes the United Nations' climate convention (UNFCCC), under which the parties negotiated the Paris Agreement (Rizvi and Hoffman, 2015). Indeed, recent years have seen an increase of global political momentum to fight AMR including the WHO 2015 Global Action Plan on AMR and similar versions by the Food and Agricultural Organisation (FAO) and World Organisation for Animal Health (OIE) (Ruckert et al., 2020), yet this momentum continues to fall short of tangible and binding commitments by the member states. Scholars have pointed out a critical "commitment-compliance gap" (Weldon and Hoffman, 2021). Many national action plans share the objectives of the WHO global action plan, but fail to back these objectives with targeted policies (Munkholm and Rubin, 2020). Dedicated international legal agreements on AMR are still missing (Rogers Van Katwyk et al., 2020a; Rogers Van Katwyk et al., 2020b), even though such binding governance mechanisms could be considered the "gold standard" in global health governance (Ruckert et al.). In order to reach global AMR action, a key challenge is achieving a global recognition of necessity (Okeke, 2009) and securing equal levels of support for stewardship activities independent of the regional incentives at stake.

At the same time, there is a risk of putting too much faith in an international agreement as the only solution to this type of global problem. Mistrust between states at the international level can 
Table 1 Conceptual categorisation and examples of different policy types in the context of CC and AMR.

\begin{tabular}{|c|c|c|c|}
\hline & Economic & Legal & Informative \\
\hline \multicolumn{4}{|c|}{ Rewarding } \\
\hline $\mathrm{CC}$ & $\begin{array}{l}\text { Subsidies for fuel-efficient vehicles (Sterner } \\
\text { and Coria, 2013). }\end{array}$ & $\begin{array}{l}\text { Access to bus lanes for fuel-efficient cars } \\
\text { (Langbroek et al., 2016). }\end{array}$ & $\begin{array}{l}\text { Information campaigns highlighting the } \\
\text { benefits of } \mathrm{CO}_{2} \text { reduction (Markowitz } \\
\text { and Shariff, 2012). }\end{array}$ \\
\hline AMR & $\begin{array}{l}\text { Financial rewards for reducing prescriptions of } \\
\text { broad-spectrum antibiotics (e.g., Bou-Antoun } \\
\text { et al., 2018). }\end{array}$ & $\begin{array}{l}\text { Additional authority and rights for medical } \\
\text { prescribers with lower antibiotic } \\
\text { prescribing rates. }\end{array}$ & $\begin{array}{l}\text { Information campaigns highlighting the } \\
\text { benefits of prudent antibiotic use (e.g., } \\
\text { Belongia et al., 2005). }\end{array}$ \\
\hline \multicolumn{4}{|c|}{ Punishing } \\
\hline $\mathrm{CC}$ & $\begin{array}{l}\text { Climate taxes for the use of fossil-fuel } \\
\text { (Sterner and Coria, 2013). }\end{array}$ & $\begin{array}{l}\text { Ban of fossil-fuel cars in urban areas (Gundlach } \\
\text { et al., 2018) }\end{array}$ & $\begin{array}{l}\text { Information campaigns shaming } \mathrm{CO}_{2-} \\
\text { emissions (Baek and Yoon, 2017). }\end{array}$ \\
\hline AMR & $\begin{array}{l}\text { Withdrawal of health funding for healthcare } \\
\text { centres with high rates of antibiotic } \\
\text { prescribing (e.g., Yip et al., 2014). }\end{array}$ & $\begin{array}{l}\text { Prohibition of "over-the-counter" sales of } \\
\text { antibiotics (e.g., Kliemann, Levin, Moura, } \\
\text { Boszczowski, and Lewis, 2016). }\end{array}$ & $\begin{array}{l}\text { Information campaigns shaming the } \\
\text { overuse of antibiotics. }\end{array}$ \\
\hline
\end{tabular}

negatively affect both the potential of reaching agreements and the likelihood of parties following signed agreements (Barrett, 2003). Moreover, global agreements will not be successful unless additional action is taken by decision makers at other levels. For example, national and local governments will have to execute the policies needed to fulfil the agreements. Furthermore, according to the polycentric approach (e.g., Ostrom, 2010), action at different levels can create opportunity for a wider variety of solutions across different contexts. This can increase learning about the kind of policies that are most successful. It can also be a strategy, through communication and reciprocal action, to increase cooperation (Ostrom, 2010; Cole, 2015). Hence, local action can have positive global effects. If a city introduces policies to reduce the number of cars to deal with local air pollution, it will also reduce overall GHG emissions. A local hospital can introduce new hygiene routines, which limit the spread of bacteria and, ultimately, the need for antibiotics.

Target group. The global scale complicates reputation-building between individual decision makers, but for "superusers" (Quail et al., 2017) of fossil fuels and antibiotics such as large industry, hospital chains or agricultural companies, reputation may play a larger role. Potentially, increased transparency about internal usage policies for critical resources could clarify how the threats of CC and AMR are approached at governance level. Here lie opportunities for companies to build reputations and distinguish themselves as either co-operators or defectors in the global dilemmas of preserving a stable climate and antibiotic drug efficacy. Examples can be found in the context of CC, where international companies strive to foster a "green" reputation built on sustainable practice that is aimed to protect the environment (Kottasová, 2018). In the agricultural context of AMR, increasing numbers of international restaurant chains are making public commitments to remove antibiotics from their supply chains (Kelso, 2021). There is of course always the risk that actors freeride on this mechanism and promote themselves under a false (green) flag (Delmas and Burbano, 2011). Thus, imposing policies that require superusers of antibiotics to publicly declare their usage rates, could be an important step in discouraging unnecessary use of antibiotics.

Additionally, our theoretical analysis highlights the importance of gate keepers, especially in the context on antibiotics use. In many countries, patients have to obtain a medical prescription prior to antibiotic use. Thus, their decision to take antibiotics is not always an individual choice but can be interpreted as interactive decision reached jointly with the gate keepers (e.g., doctors or pharmacists). Indeed, in some circumstances, the patient may not have any influence on the treatment decision.
Gate keepers clearly have a pivotal role in the protection of the antibiotic commons and this needs to be recognised in targeted policies. Just like it could help to have superusers publish their antibiotic usage rates, a possible step would be to track individual prescription rates and highlight prescribers with lower rates. The next section will focus on different types of policy designs that can be used to target decision makers in dealing with these largescale collective action problems.

Policy design. In order to design policies addressing CC and AMR, we consider the literature on rewards and punishments as a point of departure, because both have been highlighted to be important for generating cooperation (Balliet et al., 2011; Balliet and Van Lange, 2013; Fehr and Gächter, 2000). Governments may use their power to impose policies based on these. Necessary contextual adaptations and nuances can be achieved by varying the administrative designs, using different combinations of legal regulations, pricing mechanisms or information. This is demonstrated in Table 1, which provides an overview of different policy types in the context of CC and AMR. Where possible, each policy type is illustrated with reference to a real-life policy example. Our categorisation should not be understood as direct policy recommendation. Instead, it provides a theoretical framework that helps to conceptualise and understand current and potential future CC and AMR policies based on rewards and punishments.

Different policy types are likely to vary in their acceptability across the different dilemmas. For example, the punishment of defectors is a commonly accepted method of deterrence in the context of CC. Taxing polluters or imposing legal punishment for superusers of GHG emissions are often suggested by both policy experts and political decision makers to reduce emissions. Based on economic theory and the so-called "polluter-pays principle", Pigouvian carbon pricing is assumed to be both efficient and fair (Sterner and Coria, 2013). However, punitive or tax-based policies are uncommon in the regulation of antibiotic prescribing, and their potential for future use may be limited. In many developing countries, access to medication is already limited by financial factors (Laxminarayan and Heymann, 2012) and introducing a tax could discourage any future use of antibiotics even in those cases where they are the only treatment option. In many developed countries, there are subsidy schemes for medication costs, which means that if treatment costs surpass a critical target, all further medication expenditures will be covered or heavily subsidised (e.g., Anell, Glenngård and Merkur, 2012). Removing such subsidy schemes might again be ethically controversial since this action would have disproportionate implications for poorer or more vulnerable groups in society. Additionally, the ambiguous ethical labelling of antibiotic 
overuse, which is often motivated by a prescriber's best intentions to reduce patient risk, creates a moral dilemma for punitive policies in the context of antibiotic stewardship. An exception may be taxation for unnecessary use of antibiotics for growth promotion of livestock in agriculture (Laxminarayan et al., 2013; Lipsitch et al., 2002), where the concerns are reduced or even non-existent (Anomaly, 2013).

Information can reduce misconceptions about antibiotics or give better information about the carbon footprint, but information campaigns are often criticised for not being coercive enough, and there is a gap between awareness and action (Kollmuss and Agyeman, 2002). Furthermore, third-party information does not change the social dilemma characteristics per se, which means that individual decision makers still have an incentive to free-ride and defect. However, information campaigns could be efficient in order to highlight some of the unique complexities of the $\mathrm{CC}$ and AMR dilemmas, and changed norms of action can potentially be a very efficient way to deal with these problems. Through careful message framing, for example, stronger links between individual behaviour and depletion of the commons could be made, thus creating a sense of necessity and responsibility for action. Both would be crucial to pave the way for future, more coercive policies (Vedung, 1998). Additionally, information campaigns could be used to promote social norms that reinforce cooperation (Bicchieri, 2002; Henrich, 2015; Ostrom, 2000), and not just through government action. A real-life example demonstrating the importance of social norms in the sharing of information about CC is the Swedish phenomenon of "flight shame", which describes increasing social norms against air travel that gained momentum due to outspoken messages of well-known public figures shared on national media (BBC, 2020). To make strategic use of this phenomenon, governments could include similar social norm communication in national information campaigns targeting CC.

\section{Conclusions}

In this article, we investigate if and how game theory may be used to model the existential threats of CC and AMR. We further analyse how these two societal problems compare in their social, political and behavioural challenges and subsequent policy implications. While social dilemmas and especially the Tragedy of the Commons may be useful to improve our general understanding of CC and AMR, our analysis highlights a number of empirical discrepancies between game theoretical assumptions and the real-life problems. For example, real-world decision makers rarely have the autonomous, symmetrical roles assumed in game theory. Instead, the existence of "superusers" and gate keepers creates complicated networks of actors. Furthermore, choice structures are seldom categorical in the real-life contexts of CC and AMR. Most decisions include nuanced considerations and trade-offs, which are further complicated by temporal and spatial distance between choices and outcomes, and different ethical implications. Policy makers need to acknowledge the discrepancies between theory and reality when developing strategies for targeting CC and AMR. Given the global problem scales, binding, international agreements and institutions are key for coordinating national or local initiatives.

Policies may need to target influential groups of decision makers such as "superusers" (e.g., large company consumers of fossil fuels) and gate keepers (e.g., medical prescribers), and one way of doing so is to increase transparency of actions as a way to enable reputation building. Third-party intervention appears necessary, and this may involve the use of rewards and punishments in the context of varying administrative designs. With regard to specific policy design, carbon taxation is often seen as the most efficient policy to decrease climate emissions, but this needs to be introduced with great sensitivity to national perceptions of fairness. The prospects for a Pigouvian tax on antibiotics are more limited, given that such a policy would limit poorer populations' access to medication, and punish well-meaning but risk-averse medical prescribers in more developed countries. Even though information policies are somewhat limited in impact because they do not change the structural features of the underlying social dilemma, carefully framed information campaigns that help to shape new social norms, could inspire a more elaborated normative and philosophical discussion on the burden and responsibilities of CC and AMR.

\section{Data availability}

No data generated.

Received: 20 August 2020; Accepted: 26 April 2021;

Published online: 21 May 2021

\section{Note}

1 Given the public's frequent ignorance about serious side effects of antibiotics (Davies et al., 2013), the social dilemma of antibiotic use in healthcare may partly be based on misinformation and could be alleviated through more appropriately framed information.

\section{References}

Alison HH, Luke SPM, Arnfinn S, Martin S, Sadie R, Abhilasha K, Laura JVP (2016) Understanding the mechanisms and drivers of antimicrobial resistance. Lancet 387(10014):176-187. https://doi.org/10.1016/S0140-6736(15) 00473-0

Andresen S, Hoffman SJ (2015) Much can be learned about addressing antibiotic resistance from multilateral environmental agreements. J Law Med Ethics 43 (S3):46-52. https://doi.org/10.1111/jlme.12274

Anell A, Glenngård AH, Merkur S (2012) Sweden: health system review. Health Syst Trans 14(5):1-159. https://apps.who.int/iris/handle/10665/330318 https://apps.who.int/iris/handle/10665/330318

Anomaly J (2010) Combating resistance: the case for a global antibiotics treaty. Public Health Ethics 3(1):13-22. https://doi.org/10.1093/phe/phq001

Anomaly J (2013) Collective action and individual choice: rethinking how we regulate narcotics and antibiotics. J Medical Ethics 39(12):752-756

Anomaly J (2020) Antibiotics and animal agriculture: the need for global collective action. In Euzebiusz Jamrozik and Michael Selgelid (eds). Ethics and Drug Resistance: Collective Responsibility for Global Public Health. Springer Nature, 2020.: Ethics and drug resistance: collective responsibility for global public health. Springer, Cham, pp. 297-308

Ardal C, Outterson K, Hoffman SJ, Ghafur A, Sharland M, Ranganathan N, Røttingen J-A (2016) International cooperation to improve access to and sustain effectiveness of antimicrobials. Lancet 387(10015):296-307. https:// doi.org/10.1016/S0140-6736(15)00470-5

Baek TH, Yoon S (2017) Guilt and shame: environmental message framing effects. J Advert 46(3):440-453

Balliet D, Mulder LB, Van Lange PAM (2011) Reward, punishment, and cooperation: a meta-analysis. Psychol Bull 137(4):594-615. https://doi.org/ 10.1037/a0023489

Balliet DP, van Lange PAM (2013) Trust, conflict and cooperation: a meta-analysis. Psychol Bull 139(5):1090-1112. https://doi.org/10.1037/a0030939

Barrett S (2003) Environment and statecraft: the strategy of environmental treatymaking. Oxford University Press, Oxford

BBC (2020) Sweden sees rare fall in air passengers, as flight-shaming takes off. BBC News, https://www.bbc.co.uk/news/world-europe-51067440\#: :text=Sweden $\% 20$ has $\% 20$ seen $\% 20$ a $\% 204$,years $\% 20$ for $\% 20 a \% 20$ European $\% 20$ country. \&text $=$ Flygskam $\% 20$ or $\% 20 \% 22$ flight $\% 20$ shame $\% 22 \% 20$ originated,pledged $\%$ 20to\%20give\%20up\%20flying

Belongia EA, Knobloch M, Kieke BA, Davis JP, Janette C, Besser RE (2005) Impact of statewide program to promote appropriate antimicrobial drug use. Emerg Infect Dis 11(6):912-920. https://doi.org/10.3201/eid1106.050118

Bicchieri C (2002) Covenants without swords: group identity, norms, and communication in social dilemmas. Ration Soc 14(2):192-228. https://doi.org/ $10.1177 / 1043463102014002003$

Bou-Antoun S, Costelloe C, Honeyford K, Mazidi M, Hayhoe BWJ, Holmes A, Johnson AP, Aylin P (2018) Age-related decline in antibiotic prescribing for uncomplicated respiratory tract infections in primary care in England 
following the introduction of a national financial incentive (the Quality Premium) for health commissioners to reduce use of antibiotics in the community: an interrupted time series analysis. J Antimicrob Chemother 73 (10):2883-2892. https://doi.org/10.1093/jac/dky237

Bowles S, Gintis H (2008) The evolutionary basis of collective action. In: Donald A. Wittman and Barry R. Weingast (eds) The Oxford Handbook of Political Economy. vol. 4. Oxford University Press

Cole D (2015) Advantages of a polycentric approach to climate change policy. Nat Clim Change 5: 114-118. https://doi.org/10.1038/nclimate2490

Colman AM (2013) Game theory and its applications: in the social and biological sciences. Psychology Press

Colman AM, Krockow EM, Chattoe-Brown E, Tarrant C (2019) Medical prescribing and antibiotic resistance: a game-theoretic analysis of a potentially catastrophic social dilemma. PLoS ONE 14(4):e0215480. https://doi.org/ 10.1371/journal.pone. 0215480

Davies J, Davies D (2010) Origins and evolution of antibiotic resistance. Microbiol Mol Biol Rev 74(3):417-433. https://doi.org/10.1128/MMBR.00016-10

Davies DS, Grant J, Catchpole M (2013) The drugs don't work: a global threat. Penguin, UK

Dawes RM (1980) Social dilemmas. Ann Rev Psychol 31(1):169-193

Delmas MA, Burbano VC (2011) The drivers of Greenwashing. Calif Manag Rev 54 (1):64-87. https://doi.org/10.1525/cmr.2011.54.1.64

Dunlap RE, McCright AM (2011) Organized climate change denial. The Oxford handbook of climate change and society 1:144-160

Eggleston K, Zhang R, Zeckhauser RJ (2010) The global challenge of antimicrobial resistance: insights from economic analysis. Int J Environ Res Public Health 7: 3141-3149

Fehr E, Gächter S (2000) Fairness and retaliation: the economics of reciprocity. J Econ Perspect 14(3):159-182

Fischbacher U, Gächter S, Fehr E (2001) Are people conditionally cooperative? Evidence from a public goods experiment. Econ Lett 71(3):397-404. https:// doi.org/10.1016/S0165-1765(01)00394-9

Fitzpatrick F, Tarrant C, Hamilton V, Kiernan FM, Jenkins D, Krockow EM (2019) Sepsis and antimicrobial stewardship: two sides of the same coin. BMJ Qual Safety 28(9):758-761. https://doi.org/10.1136/bmjqs-2019-009445

Gundlach A, Ehrlinspiel M, Kirsch S, Koschker A, Sagebiel J (2018) Investigating people's preferences for car-free city centers: a discrete choice experiment. Transp Res Part D: Transp Environ 63:677-688

Hardin G (1968) The tragedy of the commons. Science 13(162):1243-1248

Helwig K (2019) Justice at the intersection of climate change and anti-microbial resistance. World Forum on Climate Justice. Retrieved from: https:// researchonline.gcu.ac.uk/en/publications/justice-at-the-intersection-ofclimate-change-and-anti-microbial-

Henrich J (2015) Culture and social behavior. Curr Opin Behav Sci 3:84-89. https://doi.org/10.1016/j.cobeha.2015.02.001

Hwang TJ, Gibbs KA, Podolsky SH, Linder JA (2015) Antimicrobial stewardship and public knowledge of antibiotics. Lancet Infect Dis 15(9):1000-1001. https://doi.org/10.1016/S1473-3099(15)00235-2

IPCC (2018) Global warming of $1.5^{\circ} \mathrm{C}$. An IPCC special report on the impacts of global warming of $1.5^{\circ} \mathrm{C}$ above pre-industrial levels and related global greenhouse gas emission pathways, in the context of strengthening the global response to the threat of climate change, sustainable development, and efforts to eradicate poverty. In: Masson-Delmotte V, Zhai P, Pörtner HO, Roberts D, Skea J, Shukla PR, Pirani A, Moufouma-Okia W, Péan C, Pidcock R, Connors S, Matthews JBR, Chen Y, Zhou X, Gomis MI, Lonnoy E, Maycock T, Tignor M, Waterfield T (eds.). IPCC

Jagers SC, Harring N, Löfgren $\AA$, Sjöstedt M, Alpizar F, Brülde B,... Dupont S (2020) On the preconditions for large-scale collective action. Ambio 49:1282-1296

Jakob M, Steckel JC (2014) How climate change mitigation could harm development in poor countries. WIREs Clim Change 5(2):161-168. https://doi.org/ $10.1002 /$ wcc. 260

Kelso (2021) Popeyes announces plans to remove artificial ingredients. Antibiotics, Forbes, https://www.forbes.com/sites/aliciakelso/2021/03/02/popeyesannounces-plans-to-remove-artificial-ingredients-antibiotics/? $\mathrm{sh}=594 \mathrm{fa} 67 \mathrm{~d} 5 \mathrm{c} 45$

Kliemann BS, Levin AS, Moura ML, Boszczowski I, Lewis JJ (2016) Socioeconomic determinants of antibiotic consumption in the state of São Paulo, Brazil: the effect of restricting over-the-counter sales. PLoS ONE 11(12):e0167885. https://doi.org/10.1371/journal.pone.0167885

Kollmuss A, Agyeman J (2002) Mind the gap: why do people act environmentally and what are the barriers to pro-environmental behavior? Environ Educ Res 8(3):239-260. https://doi.org/10.1080/13504620220145401

Kottasová I (2018) These companies are leading the fight against climate change. Retrieved from https://edition.cnn.com/2018/10/09/business/climate-changecompanies/index.html

Krockow EM, Colman AM, Chattoe-Brown E, Jenkins DR, Perera N, Mehtar S, Tarran C (2018) Balancing the risks to individual and society: a systematic review and synthesis of qualitative research on antibiotic prescribing behaviour in hospitals. J Hosp Infect 1-18. https://doi.org/10.1016/j. jhin.2018.08.007

Krockow EM, Tarrant C (2019) The international dimensions of antimicrobial resistance: contextual factors shape distinct ethical challenges in South Africa, Sri Lanka and the United Kingdom. Bioethics 33(7):756-765. https://doi.org/ 10.1111/bioe.12604

Langbroek JH, Franklin JP, Susilo YO (2016) The effect of policy incentives on electric vehicle adoption. Energy Policy 94:94-103

Laxminarayan R, Duse A, Wattal C, Zaidi AKM, Wertheim HFL, Sumpradit N, Cars O (2013) Antibiotic resistance-the need for global solutions. Lancet Infect Dis 13(12):1057-1097. https://doi.org/10.1016/S1473-3099(13)70318-9

Laxminarayan R, Heymann DL (2012) Challenges of drug resistance in the developing world. Br Med J 344:e1567. https://doi.org/10.1136/bmj.e1567

Lin DM, Koskella B, Lin HC (2017) Phage therapy: an alternative to antibiotics in the age of multi-drug resistance. World J Gastrointest Pharmacol Ther 8 (3):162-173. https://doi.org/10.4292/wjgpt.v8.i3.162

Lipsitch M, Singer RS, Levin BR (2002) Antibiotics in agriculture: when is it time to close the barn door? Proc Natl Acad Sci 99(9):5752-5754. https://doi.org/ 10.1073/pnas.092142499

Mansbridge J (2014) The role of the state in governing the commons. Environ Sci Policy 36:8-10. https://doi.org/10.1016/j.envsci.2013.07.006

Markowitz EM, Shariff AF (2012) Climate change and moral judgement. Nat Clim Change 2(4):243-247

Milinski M, Sommerfeld RD, Krambeck H-J, Reed FA, Rotzke JM (2008) The collective-risk social dilemma and the prevention of simulated dangerous climate change. Proc Nat Acad Sci 105(7):2291-2294

Munkholm L, Rubin O (2020) The global governance of antimicrobial resistance: a cross-country study of alignment between the global action plan and national action plans. Glob Health 16:109. https://doi.org/10.1186/s12992-020-00639-3

O’Neill J (2016) Tackling drug-resistant infections globally: final report and recommendations. Rev Antimicrob Resist 178(23):590. https://doi.org/ $10.1136 /$ vr.i3114

Okeke IN (2009) The tragedy of antimicrobial resistance: achieving a recognition of necessity. Curr Sci 97(11):1564-1572. Retrieved from http://www.jstor.org/ stable/24107296 http://www.jstor.org/stable/24107296

Olson M (2009) The logic of collective action: public goods and the theory of groups, second printing with a new preface and appendix (vol. 124). Harvard University Press

Ostrom E (1998) A behavioral approach to the rational choice theory of collective action: presidential address, American Political Science Association, 1997. Am Polit Sci Rev 92(1):1-22. https://doi.org/10.2307/2585925

Ostrom E (2000) Collective action and the evolution of social norms. J Econ Perspect 14(3):137-158

Ostrom E (2010) Polycentric systems for coping with collective action and global environmental change. Glob Environ Change 20(4):550-557. https://doi.org/ 10.1016/j.gloenvcha.2010.07.004

Ostro E, Walker J (2003) Trust and reciprocity: interdisciplinary lessons for experimental research. Russell Sage Foundation

Podolsky SH, Lie AK (2016) Futures and their uses: antibiotics and therapeutic revolutions. Therapeutic revolutions: pharmaceuticals and social change in the twentieth century. University of Chicago Press, Chicago, pp. 18-42

Premanandh J, Samara BS, Mazen AN (2016) Race against antimicrobial resistance requires coordinated action-an overview. Front Microbiol 6(1536). https:// doi.org/10.3389/fmicb.2015.01536

Quail J, Anderson M, Osman M, de Oliveira C, Wodchis W, Muhajarine, N,... Teare G (2017) Identifying superusers of health services with mental health and addiction problems. International J Popul Data Sci 1(1)

Rawson TM, Charani E, Moore LSP, Hernandez B, Castro-Sánchez E, Herrero P, Georgiou P, Holmes AH (2016) Mapping the decision pathways of acute infection management in secondary care among UK medical physicians: a qualitative study. BMC Med 14(1)

Rizvi Z, Hoffman SJ (2015) Effective global action on antibiotic resistance requires careful consideration of convening forums. J Law Med Ethics 43(S3):74-78. https://doi.org/10.1111/jlme.12278

Robertson F, Jagers S, Rönnerstrand B (2018) Managing sustainable use of antibiotics-the role of trust. Sustainability 10(2):143. https://doi.org/10.3390/ su10010143

Rogers Van Katwyk S, Grimshaw JM, Nkangu M, Nagi R, Mendelson M, Taljaard $\mathrm{M}$ et al. (2019) Government policy interventions to reduce human antimicrobial use: a systematic review and evidence map. PLoS Med 16(6): e1002819. https://doi.org/10.1371/journal.pmed.1002819

Rogers Van Katwyk S, Giubilini A, Kirchhelle C et al. (2020a) Exploring models for an international legal agreement on the global antimicrobial commons: lessons from climate agreements. Health Care Analy. https://doi.org/10.1007/ s10728-019-00389-3

Rogers Van Katwyk S, Weldon I, Giubilini A, Kirchhelle C, Harrison M, McLean A, Hoffman SJ (2020b) Making use of existing international legal 
mechanisms to manage the global antimicrobial commons: identifying legal Hooks and institutional mandates. Health Care Anal 1-16. https://doi.org/ 10.1007/s10728-020-00393-y

Roope LSJ, Smith RD, Pouwels KB, Buchanan J, Abel L, Eibich P, Wordsworth S (2019) The challenge of antimicrobial resistance: what economics can contribute. Science 364(6435):eaau4679. https://doi.org/10.1126/science.aau4679

Rose CM (2009) Liberty, property, environmentalism. Soc Philos Policy 26(1):10-19

Ruckert A, Fafard P, Hindmarch S et al. (2020) Governing antimicrobial resistance: a narrative review of global governance mechanisms. J Public Health Policy 41:515-528. https://doi.org/10.1057/s41271-020-00248-9

Sterner T, Coria J (2013). Policy instruments for environmental and natural resource management. Routledge

Tarrant C, Colman AM, Chattoe-Brown E, Jenkins DR, Mehtar S, Perera N, Krockow EM (2019) Optimizing antibiotic prescribing: collective approaches to managing a common-pool resource. Clin Microbiol Infect https://doi.org/ 10.1016/j.cmi.2019.03.008

Tarrant C, Colman AM, Jenkins DJ, Chattoe-Brown E, Perera N, Mehtar S, Nakkawita D, Bolscher M, Krockow EM (2021) Broad spectrum antibiotic overuse as a solution to structural problems? A qualitative study of hospital prescribers in the UK, Sri Lanka and South Africa. Antibiotics 10(1):94. https://doi.org/10.3390/antibiotics10010094

Tarrant C, Krockow EM, Nakkawita D, Bolscher M, Colman AM, Chattoe-Brown E, Perera N, Mehtar S, Jenkins DR (2020) Moral and contextual dimensions of "inappropriate" antibiotic prescribing in secondary care: a three-country interview study. Front Sociol 5:7. https://doi.org/10.3389/fsoc.2020.00007

Vedung E (1998) Policy instruments: typologies and theories. In: BemelmansVidec ML, Rist RC, Vedung EO (Ed.) Carrots, sticks \& sermons: policy instruments and their evaluation. Transaction publishers, New Brunswick, USA, pp. 21-58

Weldon I, Hoffman SJ (2021) Bridging the commitment-compliance gap in global health politics: lessons from international relations for the global action plan on antimicrobial resistance. Glob Public Health 16:60-74. https://doi.org/ $10.1080 / 17441692.2020 .1788623$

Yip W, Powell-Jackson T, Chen W, Hu M, Fe E, Hu M, Jian W, Lu M, Han W, Hsiao WC (2014) Capitation combined with pay-for-performance improves antibiotic prescribing practices in rural China. Health Aff 33(3):502-510. https://doi.org/10.1377/hlthaff.2013.0702

\section{Acknowledgements}

We thank Fredrik Carlsson and Martin Sjöstedt and the participants the CeCAR Workshop 5-6 December 2019 and the CARe Intervention group workshop 15 January 2020 where early drafts of this manuscript were presented.

\section{Funding}

Open access funding provided by University of Gothenburg.

\section{Competing interests}

The authors declare no competing interests.

\section{Additional information}

Correspondence and requests for materials should be addressed to N.H.

Reprints and permission information is available at http://www.nature.com/reprints

Publisher's note Springer Nature remains neutral with regard to jurisdictional claims in published maps and institutional affiliations.

\begin{abstract}
(c) (i) Open Access This article is licensed under a Creative Commons Attribution 4.0 International License, which permits use, sharing, adaptation, distribution and reproduction in any medium or format, as long as you give appropriate credit to the original author(s) and the source, provide a link to the Creative Commons license, and indicate if changes were made. The images or other third party material in this article are included in the article's Creative Commons license, unles indicated otherwise in a credit line to the material. If material is not included in the article's Creative Commons license and your intended use is not permitted by statutory regulation or exceeds the permitted use, you will need to obtain permission directly from the copyright holder. To view a copy of this license, visit http://creativecommons.org/ licenses/by/4.0/.
\end{abstract}

(C) The Author(s) 2021 